\title{
Operative approaches for debris flow modelling and hazard assessment, Laures watershed, Valle d'Aosta, Italy
}

\author{
M. Segato ${ }^{1}$, L. Mao ${ }^{1}$, M. Coccato ${ }^{2}$, M. A. Lenzi ${ }^{1}$ \& V. D’Agostino ${ }^{1}$ \\ ${ }^{1}$ Department of Land and Agroforest Environments, \\ University of Padova, Italy \\ ${ }^{2}$ BETA Studio s.r.l., Padova, Italy
}

\begin{abstract}
Here is presented a comparative application of different simple methods for preliminary hazard mapping in debris flow prone areas. The analysis is carried out in the Laures fan, a $17.2 \mathrm{~km}^{2}$ basin in the Western Italian Alps. The applied methods support increasing complexities, starting from the use of a simplified hydraulic approach for the identification of the critical cross-sections and the overflow volume to the use of a 2-D model that provides a hazard map from the overlay of maximum flow thickness and velocity maps. If integrated with a deep knowledge of the fan area, the first approach allows a reasonable preliminary debris flow hazard mapping. The use of a 2-D hydrodynamic model is recommended if inhabited area or important communications are located in the fan, thus a more accurate hazard mapping is required.
\end{abstract}

Keywords: alps, debris flow, hazard mapping, 2-D model.

\section{Introduction}

Debris flows are one of the most hazardous natural phenomena in the European Alps. Debris flows frequently reaches the mountains alluvial fans, where commonly houses, infrastructures, and crops are located, and where the channel slope becomes milder thus allowing debris deposition and causing backwater effects and upstream flooding. Even if these events regularly cause loss of life, and disruption of livelihood and communications, in Europe there are still no uniform approach and available quantitative techniques for limit this hazard. 
Any human development on a debris flow-susceptible fan is exposed to a risk that is extremely expensive and difficult to manage with the traditional hydraulics structural measures as construction of levees, check-dams or channel rectifications. Non-structural instruments as hazard zoning, in addition to technical solutions, is thus needed in debris flow risk management planning. It is important to bear in mind that the risk concept is connected with size, value and probability of possible damages and vulnerability of potential damageable objects. Conversely, hazard concept lacks this connection with land use, and hazard zoning do not consider the potential damage objects and their value [Buwal, 1998]. Debris flow natural hazards are characterised by a close relationship to basin geology, size and sediment availability and topographical fan features. Numerous topographical, hydrological and sedimentological information is required, and the lacking of a uniform approach and standard techniques make a challenge the implementation of hazard maps by the local planning institutions.

In the present paper a comparative application of three methods for preliminary hazard mapping is carried out in the Laures basin $\left(17.2 \mathrm{~km}^{2}\right)$ in the Western Italian Alps.

\section{The Laures basin}

The Laures basin $\left(17.2 \mathrm{~km}^{2}\right)$ is located in the Val d'Aosta region in the western Italian Alps. The basin shows an elliptical form, with the main axis orientated in S-N direction. The Laures basin reaches 3,357 $\mathrm{m}$ a.s.l. (Grande Roise) and closes at $532 \mathrm{~m}$ a.s.l. (tab. 1). The upper part of the main valley is characterized by various geological steps which originate lakes at different altitudes (Lac Jacquin, 2,941 m; Lac D’En haut, 2,788 m; Lago Lungo, 2,630 m; Lago Inferiore, $2,545 \mathrm{~m})$. The mean slope of the upper part of the valley $(3,357-2,500 \mathrm{~m}$ a.s.1.) is $11 \%$, whereas in its middle part become steeper (43\%). The main channel within the debris fan $\left(0.82 \mathrm{~km}^{2}\right)$ is $900 \mathrm{~m}$ long and its mean slope is $6.3^{\circ}$. The fan is mainly composed by ancient glacier deposits, covered by 1-1.5 m of alluvial debris. Three villages (Moulin, Etabloz and Neyran) and a significant road network are located in the fan.

Table 1: $\quad$ The main characteristics of the Laures basin, stream and fan.

\begin{tabular}{ll}
\hline Basin area $\left(\mathrm{km}^{2}\right)$ & 17.2 \\
Minimum elevation (m a.s.l.) & 532 \\
Maximum elevation (m a.s.l.) & 3,559 \\
Gravelius factor & 1.46 \\
Mean hillslopes gradient $(\%)$ & 63 \\
Length of the main channel $(\mathrm{km})$ & 10.2 \\
Mean gradient of the main channel $(\%)$ & 23 \\
Fan area $\left(\mathrm{km}^{2}\right)$ & 0.82 \\
Length of the main channel in the fan $(\mathrm{km})$ & 0.9 \\
Mean gradient of the channel in the fan $\left(^{\circ}\right)$ & 6.3 \\
\hline
\end{tabular}


Geologically, the basin is characterized by different lithologies which emerge at different altitudes. In the lower part of the basin (530-900 m a.s.l.) dominates metamorphic rocks, constitutes by gneiss and ortogneiss, and originates by intrusive granites [2].

Small glaciers are still present near the peaks, and recent moraine deposits are present. Overall, recent and quaternary deposits are abundant in the upper part of the basin (up to 2,500 $\mathrm{m}$ a.s.l.), where no vegetation is established. The deposits are composed of medium to fine incoherent matrix with very coarse clasts $(>1 \mathrm{~m})$. Other deposits are present along the valley as lateral moraine and talus slopes.

\section{Debris-flow magnitude assessment}

The Laures valley has suffered from various debris-flows phenomena. However no monitoring systems are available in the study area, debris flow events are mentioned by ancient and recent chronicle because of material damage and causalities. An historical analysis shows that sediment triggering for debris flows has been mainly furnished by three small sub-basin of the valley: the Mont Pere Laurent North, the Mont Pere Laurent South and the Meyes.

A recent debris flow event occurred on the $27^{\text {th }}$ July 2003. The quasiunlimited sediment availability of the Mont Pere Laurent South, allowed to a very brief but intense summer rainfall to cause a debris-flow that flowed to the Laures fan. The origin, period of occurrence and behaviours of the phenomena are typical of those that commonly occur on the Laures fan. Direct observations of the event and of the sediment deposits show the very viscous behaviour of the fluid (fig. 1). Actually, the viscous nature of the debris flows depends more to the very low water quantity (25-30\% of the total) than to a modest presence of granular components.

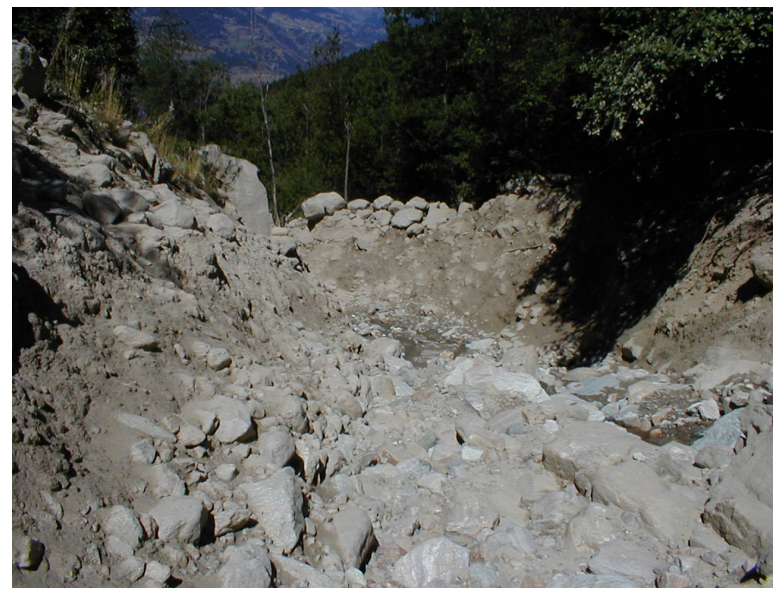

Figure 1: Deposits of the 27th July 2003 debris flow along the Laures main channel. 
The quantification of debris flows potential magnitude is one of the major requirements in the debris flows hazard assessment [1]. Different methods for debris-flow magnitude assessment have been tested. Since the high geological heterogeneity of the basin, the D'Agostino et al.[1] empirical formula has been finally used. The D'Agostino et al.[1] formula have been calibrated for small mountain basin, and supply the estimation of the event magnitude of the event as a function of morphometric parameters and geologic characteristics of the basins:

$$
V=45 A^{0.9} S^{1.5} I G
$$

where $V$ represents the potential magnitude (volume) of a debris flow event (in $\mathrm{m}^{3}$ ), $A$ the basin area (in $\mathrm{km}^{2}$ ), $S$ the average slope of the channel (in \%) and $I G$ the geolithologic index.

To apply eq. (1) to the Mont Pere Laurent North sub-basin (which demonstrates to be the most active one), we assumed an extension of the basins equal to $1.03 \mathrm{~km}^{2}$. The potential debris flow magnitude for the Mont Pere Laurent North sub-basins resulted to be $62,000 \mathrm{~m}^{3}$.

\section{Debris-flow hazard assessment}

Here we report about three very easy-to-use and user-friendly methodologies for a first and rough assessment of debris flow impact and, consequently, debris flow hazard mapping of the Laures fan. The first method is a simplified hydraulic approach, and the other consists on the application of the hydrodynamic model FLO-2D [5, 6].

\subsection{The simplified hydraulic approach}

A detailed topographical survey of the channel flowing on the fan is available. The length of the surveyed channel $(1,200 \mathrm{~m})$ starts from the apex of the fan and ends at the confluence with the higher order stream (Dora Baltea River). Along the channel there are different segments characterized by undisturbed alluvial reaches, longitudinal protection, bed sills and concrete covered reaches. In 2002 50 selected cross-sections were also surveyed by using a total station. The channel presents a nearly-trapezoidal shape, with an average width of $20 \mathrm{~m}$ and depth of 2.5-3 m.

The simulated scenario considers a relatively brief debris flow $(0.5 \mathrm{~h})$ transporting the $62,000 \mathrm{~m}^{3}$ of sediments potentially furnished by the Mont Pere Laurent North sub-basin, thus the hypothesized triangular hydrograph peaks at $70 \mathrm{~m}^{3} \mathrm{~s}^{-1}$ (fig. 2). The values of volumetric sediment concentration $C_{v}$ were varied during the hydrograph, reaching its maximum of 0.55 during the peak.

Because of the typical viscous behaviour of debris flows occurring along the Laures channel, the Hungr et al.[3] formula was adopted. Expressed for a trapezoidal cross section it gives:

$$
Q_{p}=A\left(\frac{\gamma_{s} h_{p}^{2} i}{5 \mu_{f}}\right)
$$


where $Q_{p}$ is the peak discharge in $\mathrm{m}^{3} \mathrm{~s}^{-1}$, A is the cross-section area in $\mathrm{m}^{2}, \gamma_{s}$ is the flux specific weight in $\mathrm{N} \mathrm{m}^{3}, h_{p}$ is the thickness of the debris flow front in $\mathrm{m}$, $i$ is the reach slope in $\mathrm{m} \mathrm{m}^{-1}$, and $\mu_{f}$ is the viscosity of the flux in $\mathrm{Pa} \mathrm{s}$ (here we used 3,000 $\mathrm{Pa}$ s as a prudential value [3]).

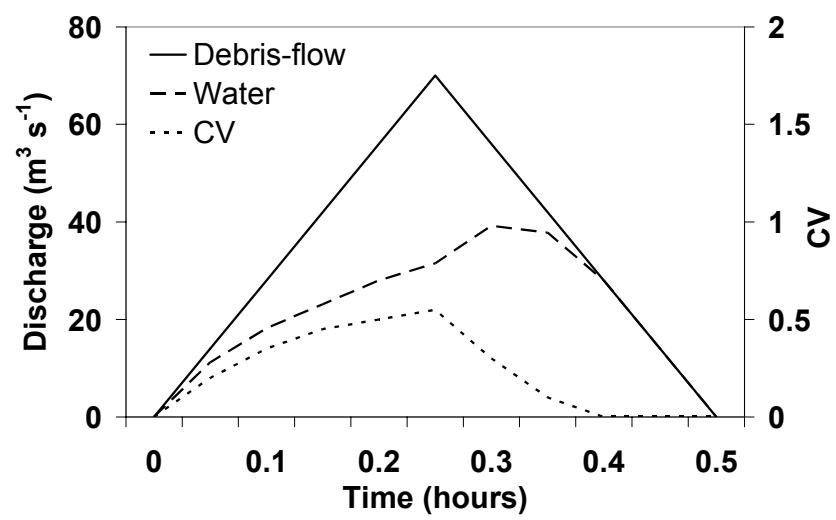

Figure 2: Simulated debris flow hydrograph and volumetric sediment concentration $(\mathrm{CV})$.

The conveyance of each cross section was compared to the debris flow hydrograph, and the overflow volume (on the right and/or left bank) was then calculated. Overall, three critical cross-sections (i.e. those showing overflow volumes) were recognized.

A preliminary hazard map was then elaborated using the Ikeya [4] formula that permits to assess the maximum run-out distances depending on a debris flow volume and on slope of the debris flow path. The latter was estimated using both digital map of the fan and geomorphologic field evidence (i.e. the thickness of deposits of past debris flows). In the elaborated map (fig. 3), the dashed area represents the hazard zone, calculated as the spreading area of the $62,000 \mathrm{~m}^{3}$ debris flow volume, with a thickness of $1 \mathrm{~m}$.

Aiming to refine this hazard map, the ability of the fan to convey the debris flow material was evaluated considering both its morphology and its land use. The morphology of the fan was described by a 10x10 DEM obtained from a 1:5,000 map of the region. The land-use map of the fan was derived from the interpretation of a recent aerial photograph and field inspections. Seven groups of land-use classes were defined, and the degree of debris flow conveyance was assigned to each of them. Assessing 1 and 0 as minimum and maximum resistance to a debris flow, respectively, the values for the different land-use classes were given as follows: 0.1 to urbanized areas, 0.15 to graze land and forested areas, 0.3 to channels and 0.4 to road network. Finally, using both the "conveyance ability" and the slope map of the fan, a rough debris flow hazard map was derived (fig. 3) considering the above calculated overflow volumes and a thickness of $1 \mathrm{~m}$ for delimitate the hazard areas. 

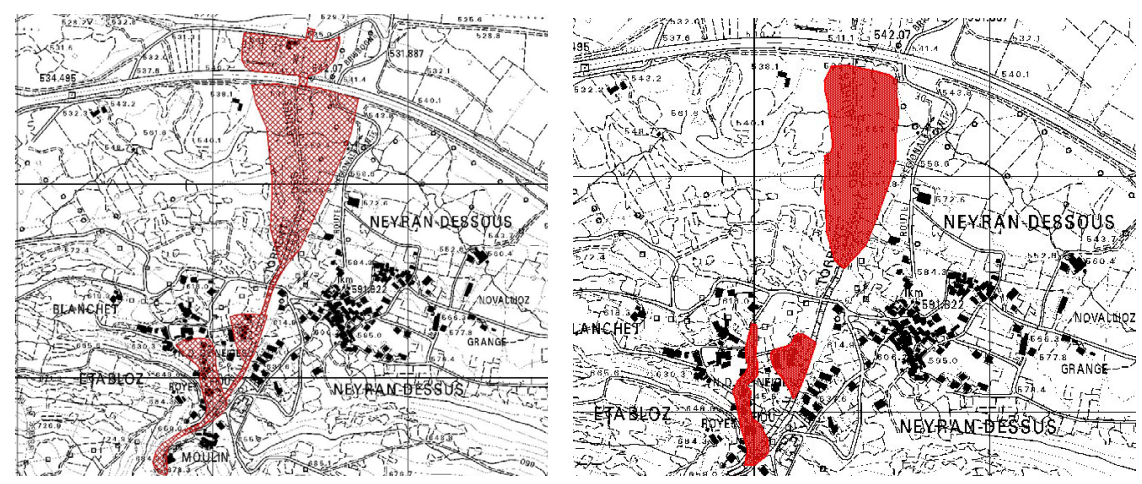

Figure 3: Debris flow hazard map for the Laures fan, obtained using: a maximum run-out distances formula (on the left), and a debris flow "conveyance ability" map of the fan (on the right).

\subsection{Application of a hydrodynamic model}

In order to obtain a debris flow hazard map of the Laures debris fan, the quasi two-dimensional flood routing commercial model FLO-2D [5] have been used. FLO-2D is a simple volume conservation model that distributes a flood hydrograph over a system of square grid element [5]. The model is able to route non-Newtonian flows, mainly described by the definition of their volumetric sediment concentration $\left(C_{v}\right)$. A quadratic rheologic model for predicting viscous and yield stresses as a function of sediment concentration is employed and sediment continuity is applied. Since four rheological parameters are needed, various empirical relationships are available and can be used to relate viscosity and yield stress to $C_{v}$ [5]. The simulated hydrograph and the values of volumetric sediment concentration $C v$ are those showed in figure 2.

A $10 \times 10 \mathrm{~m}$ digital elevation model (DEM) of the Laures fan area was obtained from a digital map $(1: 5,000)$ of the region. Once the potential flow surface in the fan was defined, the grid element roughness was assigned. Manning roughness coefficient was evaluated to be 0.05 and 0.08 in the main channel and in the adjacent cells, respectively.

Table 2: $\quad$ Maximum flow depths $\left(h_{\max }\right)$, and velocities $\left(V_{\max }\right)$ and extensions of flooded area $(A)$ obtained using four different debris flow rheology scenario in the FLO-2D model.

\begin{tabular}{lccc}
\hline \multicolumn{1}{c}{ Rheology } & $h_{\max }(\mathrm{m})$ & $V_{\max }(\mathrm{m})$ & $A\left(\mathrm{~m}^{2}\right)$ \\
\hline Aspen Pit 1 & 4.8 & 1.8 & 147,700 \\
Glenwood 4 & 3.7 & 2.1 & 164,600 \\
Dai et al. (1980) & 3.0 & 1.8 & 157,100 \\
Kang and Zhang (1980) & 1.5 & 2.8 & 189,500 \\
\hline
\end{tabular}

In order to test different debris flow scenario, four rheologic values groups were adopted and maps of maximum flow depth and maximum velocity for each 
grid element were obtained. In table 2, the maximum values of flow depth $\left(h_{\max }\right)$ and velocity $\left(V_{\max }\right)$ obtained using the four rheology values groups are reported. The extension of flooded area in the fan $(A)$ are also reported. Finally, the socalled Aspen Pit 1 rheology [5] was chosen to be characterize by viscosity and yield stress that better match the behaviours of recent events (relatively slow and thick fluxes).

Considering the Aspen Pit 1 scenario, the maps of maximum flow depths and velocities (fig. 4) were interpolated in order to obtain the hazard map.

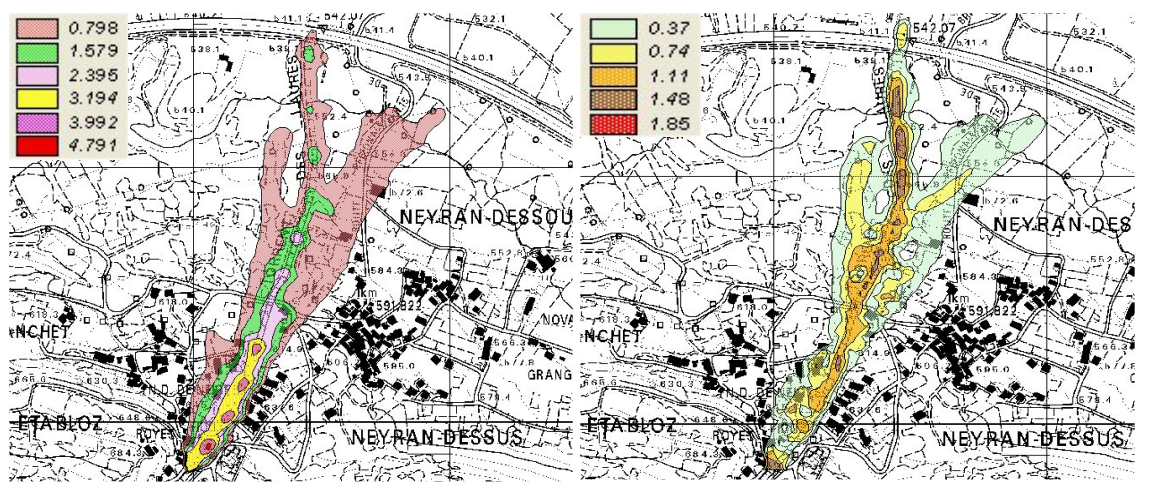

Figure 4: Maps of maximum flow depths (left, values in $\mathrm{m}$ ) and maximum flow velocity (right, values in $\mathrm{m} \mathrm{s}^{-1}$ ) on the Laures fan.

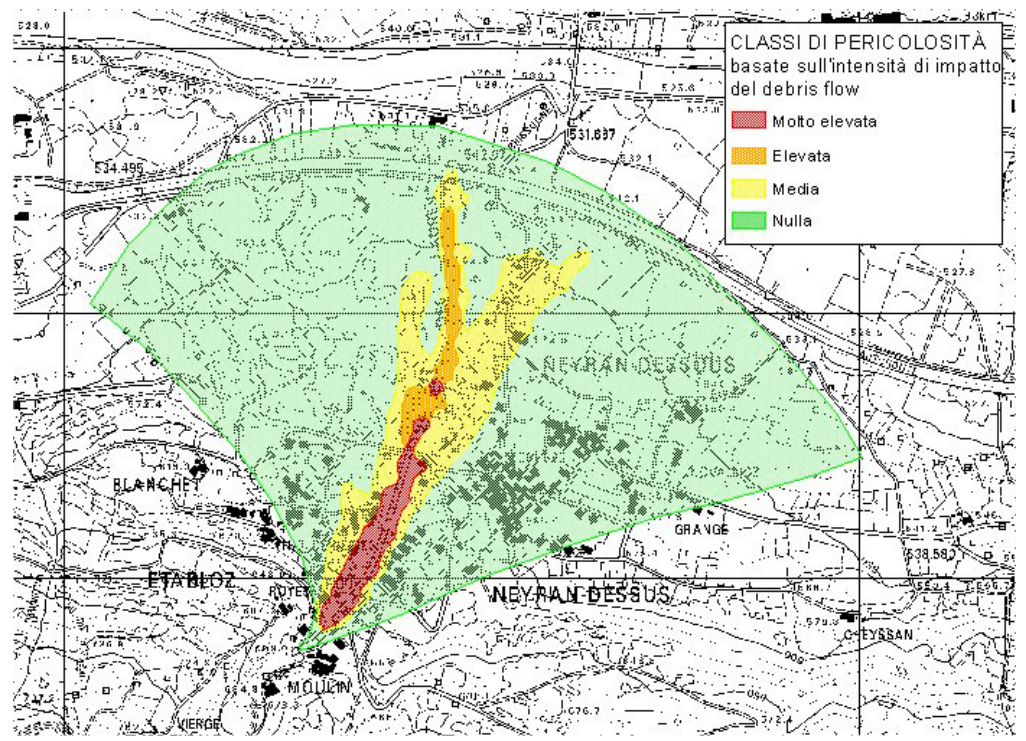

Figure 5: Debris flow hazard map for the Laures fan obtained using the FLO2-D hydrodynamic model. 
The debris flow hazard map (fig. 5) was produced by overlying the maps of maximum depth and maximum velocities of the debris flows (fig. 4) and classifying the hazard levels as expressed in table 3 .

Table 3: Hazard levels classification.

\begin{tabular}{llll}
\hline Very high hazard & $h_{\max }>1.5 \mathrm{~m}$ & and & $V_{\max }>1.5 \mathrm{~m} \mathrm{~s}^{-1}$ \\
High hazard & $1.5 \mathrm{~m}>h_{\max }>1 \mathrm{~m} \quad$ and & $1.5 \mathrm{~m} \mathrm{~s}^{-1}>V_{\max }>1 \mathrm{~m} \mathrm{~s}^{-1}$ \\
Medium hazard & $h_{\max }<1 \mathrm{~m}$ & and & $V_{\max }<1 \mathrm{~m} \mathrm{~s}^{-1}$ \\
No hazard & no flows over the cells & \\
\hline
\end{tabular}

\section{Discussion}

By using the simplified hydraulic approach (Eq. (2)) to quantify the overflow volume in the critical cross-sections, two methodologies were used in order to produce a hazard mapping of the Laures fan area. Both the run-out distances and the "conveyance ability" approaches provided comparable maps in terms of hazard area shape and extension $\left(106,000\right.$ and $70,000 \mathrm{~m}^{2}$, respectively). Due to the topography of the fan, the area on the left side of the channel resulted to be more susceptible to debris flow hazard. This preliminary debris flow hazard mapping was refined by using the FLO-2D model, and the hazard areas match rather well. The FLO-2D model permitted to better define the hazards in the lower part of the fan, where the presence of a hump force the flow to split in two ways. The extension of the hazard area is larger but comparable $\left(147,700 \mathrm{~m}^{2}\right)$ with those obtained with the simplest methods described above. However, the use of a mathematical model reduces the subjectivity in the hazard area delimitation, thus limiting the controversy in the public acceptance of the results. The zoning obtained by FLO-2D also permits to differentiate the hazard level in three classes by interpolating maps of maximum flows thickness and velocity. The use of a hydrodynamic model does not need more data acquisition and allows hypothesizing different debris flow magnitudes and rheology scenarios. The ability to quickly perform hazard mapping under different possible scenarios of in-stream structural risk mitigation projects is very valuable.

\section{Conclusions}

Due to the lack of a standard approach to debris flow hazard mapping for the fan of small alpine basins, a test of three different methods have been carried out in the Laures basin that exhibits a typical alpine debris fan. These methods features increasingly complexities, starting from the use of a simplified debris flow discharge - front depth relationship for the identification of critical cross-sections and the overflow volume to the use of a 2-D model that provide maps of maximum flows thickness and velocity. The quantification of overflow volumes make hazard mapping to requires several field surveys and leave space to subjectivity. However, the procedure is very immediate and recommendable for 
a preliminary mapping. If integrated with a deep knowledge of the area, this approach allows a reasonable debris flow hazard mapping. On the other hand, the hydrodynamic model permits to obtain less subjective results and do not require more data acquisition. Furthermore, the FLO-2D model is easy to be used by the local users' technicians. It is recommended if inhabited areas or important infrastructures are located in the fan, thus requiring a more accurate hazard mapping.

\section{Acknowledgements}

Part of the activity was supported by the "Epic Force" Project EC INCO-CT2004-510735. Luca Mao has been supported by the University of Padova Project "Valutazione della pericolosità connessa a colate detritiche su conoidi alpini".

\section{References}

[1] D’Agostino, V., Cerato, M., \& Coali, R., Il trasporto solido di eventi estremi nei torrenti del Trentino orientale. Proc. of International Symposium Interpraevent, Garmisch-Partenkirchen, Germany, 1, pp. 377-386, 1996.

[2] Dal Piaz, G.V., Le Alpi dal M. Bianco al Lago Maggiore. Società Geologica Italiana, BE-MA, 1992.

[3] Hungr, O., Morgan, G.C., \& Kellerhals, R., Quantitative analysis of debris torrent hazards for design of remedial measures. Canadian Geotechnical Journal, 21, pp. 663-677, 1984.

[4] Ikeya, H., A method of designation for area in danger of debris flow. Symp. on Erosion and Sedimentation in Pacific Rim Steepland, IAHS-AIHS Pub. N. 132, pp. 576-588, 1981.

[5] O’Brien J.S., Julien P.Y., Fullerton W.T., Two-dimensional water flood and mudflow simulation. J. of Hydr. Eng., ASCE, 119(2), pp. 244-259, 1993.

[6] FLO-2D, 2-Dimensional Flood Routine Model Manual. Version 2004.10. FLO-2D Software Inc., Nutrioso, AZ 85932, 2004. 